\title{
Front Matter: Volume 8095
}

, "Front Matter: Volume 8095," Proc. SPIE 8095, Active Photonic Materials IV, 809501 (26 September 2011); doi: 10.1117/12.905035

SPIE Event: SPIE NanoScience + Engineering, 2011, San Diego, California, United SPIE. States 


\section{PROCEEDINGS OF SPIE}

\section{Active Photonic Materials IV}

Ganapathi S. Subramania

Stavroula Foteinopoulou

Editors

22-25 August 2011

San Diego, California, United States

Sponsored and Published by

SPIE

Volume 8095

Proceedings of SPIE, 0277-786X, v. 8095 
The papers included in this volume were part of the technical conference cited on the cover and title page. Papers were selected and subject to review by the editors and conference program committee. Some conference presentations may not be available for publication. The papers published in these proceedings reflect the work and thoughts of the authors and are published herein as submitted. The publisher is not responsible for the validity of the information or for any outcomes resulting from reliance thereon.

Please use the following format to cite material from this book:

Author(s), "Title of Paper," in Active Photonic Materials IV, edited by Ganapathi S. Subramania, Stavroula Foteinopoulou, Proceedings of SPIE Vol. 8095 (SPIE, Bellingham, WA, 2011) Article CID Number.

ISSN 0277-786X

ISBN 9780819487056

Published by

SPIE

P.O. Box 10, Bellingham, Washington 98227-0010 USA

Telephone +1 3606763290 (Pacific Time) · Fax +1 3606471445

SPIE.org

Copyright (C) 2011, Society of Photo-Optical Instrumentation Engineers

Copying of material in this book for internal or personal use, or for the internal or personal use of specific clients, beyond the fair use provisions granted by the U.S. Copyright Law is authorized by SPIE subject to payment of copying fees. The Transactional Reporting Service base fee for this volume is $\$ 18.00$ per article (or portion thereof), which should be paid directly to the Copyright Clearance Center (CCC), 222 Rosewood Drive, Danvers, MA 01923. Payment may also be made electronically through CCC Online at copyright.com. Other copying for republication, resale, advertising or promotion, or any form of systematic or multiple reproduction of any material in this book is prohibited except with permission in writing from the publisher. The CCC fee code is $0277-786 \mathrm{X} / 11 / \$ 18.00$.

Printed in the United States of America.

Publication of record for individual papers is online in the SPIE Digital Library.

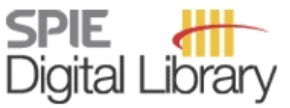

SPIEDigitalLibrary.org

Paper Numbering: Proceedings of SPIE follow an e-First publication model, with papers published first online and then in print and on CD-ROM. Papers are published as they are submitted and meet publication criteria. A unique, consistent, permanent citation identifier (CID) number is assigned to each article at the time of the first publication. Utilization of CIDs allows articles to be fully citable as soon as they are published online, and connects the same identifier to all online, print, and electronic versions of the publication. SPIE uses a six-digit CID article numbering system in which:

- The first four digits correspond to the SPIE volume number.

- The last two digits indicate publication order within the volume using a Base 36 numbering system employing both numerals and letters. These two-number sets start with 00, 01, 02, 03, 04, $05,06,07,08,09,0 A, 0 B \ldots 0 Z$, followed by 10-1Z, 20-2Z, etc.

The CID number appears on each page of the manuscript. The complete citation is used on the first page, and an abbreviated version on subsequent pages. Numbers in the index correspond to the last two digits of the six-digit CID number. 


\section{Contents}

vii Conference Committee

ix Introduction

\section{GAIN MATERIAL DYNAMICS IN PATTERNED ELECTROMAGNETIC ENVIRONMENT}

809504 Dynamics of light amplification and gain in nano-plasmonic fishnet metamaterials (Invited Paper) [8095-03]

S. Wuestner, A. Pusch, K. L. Tsakmakidis, J. M. Hamm, O. Hess, Imperial College London

(United Kingdom)

FUNCTIONAL PHOTONIC MATERIALS

809506 Quantum dot focal plane array with plasmonic resonator (Invited Paper) [8095-05]

S. Krishna, Ctr. for High Technology Materials, Univ. of New Mexico (United States)

809508 Periodic silicon nanostructures for spectroscopic microsensors [8095-59]

R. B. Wehrspohn, Martin-Luther-Univ. (Germany) and Fraunhofer Institute for Mechanics of Materials (Germany); B. Gesemann, D. Pergande, T. M. Geppert, S. L. Schweizer, Martin-Luther-Univ. (Germany); S. Moretton, A. Lambrecht, Fraunhofer-Institut für Physikalische Messtechnik (Germany)

\section{NON-LINEAR PHENOMENA AND DEVICES}

809509 On-chip stimulated Brillouin scattering (Invited Paper) [8095-07]

R. Pant, The Univ. of Sydney (Australia); C. G. Poulton, Univ. of Technology, Sydney (Australia); D.-Y. Choi, The Australian National Univ. (Australia); E. Li, The Univ. of Sydney (Australia); S. J. Madden, B. Luther-Davies, The Australian National Univ. (Australia); B. J. Eggleton, The Univ. of Sydney (Australia)

8095 OA Slotted nanobeam microcavities enabling hybrid photonic devices [8095-08]

J. Schilling, C. Schriever, C. Bohley, Martin-Luther-Univ. Halle-Wittenberg (Germany)

8095 OE Second harmonic nanoparticles in imaging applications (Invited Paper) [8095-12] Y. Pu, Ecole Polytechnique Fédérale de Lausanne (Switzerland); C.-L. Hsieh, Ecole Polytechnique Fédérale de Lausanne (Switzerland) and California Institute of Technology (United States); R. Grange, Ecole Polytechnique Fédérale de Lausanne (Switzerland) and Friedrich Schiller Univ. (Germany); X. Yang, I. Papadopoulos, J.-W. Choi, D. Psaltis, Ecole Polytechnique Fédérale de Lausanne (Switzerland)

\section{DYNAMIC CONTROL OF COMPLEX PHOTONIC MEDIA}

80950 Ol Optical response of a slab with time-periodic dielectric function $\varepsilon(t)$ : towards a dynamic metamaterial [8095-15]

P. Halevi, U. Algredo-Badillo, J. R. Zurita-Sánchez, Instituto Nacional de Astrofísica, Óptica y

Electronica (Mexico) 
$80950 \mathrm{~J} \mathrm{Modeling} \mathrm{of} \mathrm{ultrafast} \mathrm{recovery} \mathrm{times} \mathrm{and} \mathrm{saturation} \mathrm{intensities} \mathrm{of} \mathrm{the} \mathrm{intersubband}$ absorption in InGaAs/AIAs/AIAsSb coupled double quantum wells [8095-16]

P. Ma, Y. Fedoryshyn, H. Jäckel, ETH Zürich (Switzerland)

\section{MAGNETO-PHOTONIC AND PT SYMMETRIC MEDIA}

$8095 \mathrm{OL} \quad$ Optical diodes in nonlinear structures with parity-time symmetries (Invited Paper) [8095-18] H. Ramezani, Z. Lin, T. Kottos, Wesleyan Univ. (United States); D. N. Christodoulides, CREOL, The College of Optics and Photonics, Univ. of Central Florida (United States)

8095 ON Time-reversal and nonlocal effects in PT-symmetric nonlinear lattices with balanced gain and loss (Invited Paper) [8095-20]

A. A. Sukhorukov, Z. Xu, The Australian National Univ. (Australia); S. V. Dmitriev, S. V. Suchkov, Institute for Metals Superplasticity Problems (Russian Federation); Y. S. Kivshar, The Australian National Univ. (Australia)

\section{LASING IN RANDOM PHOTONIC MEDIA}

809500 Ultrafast active control of optical transmission pseudomodes in a multiple scattering nanowire layer [8095-24]

M. Abb, T. Strudley, P. Venn, Univ. of Southampton (United Kingdom); E. P. A. M. Bakkers, Technische Univ. Eindhoven (United Kingdom); O. L. Muskens, Univ. of Southampton (United Kingdom)

8095 OP Spatial coherence of random laser emission (Invited Paper) [8095-21]

B. Redding, Yale Univ. (United States); M. A. Choma, Yale School of Medicine (United States);

H. Cao, Yale Univ. (United States)

8095 OR Random lasing in disordered arrays of ZnO nanorods [8095-23]

R. Frank, Karlsruher Institut für Technologie (Germany); A. Lubatsch, Rheinische

Friedrich-Wilhelms-Univ. Bonn (Germany)

LIGHT MATTER INTERACTION: STRONG COUPLING AND CAVITY QED I

8095 OT Strong coupling of plasmons with confined modes in a quantum metamaterial [8095-26]

A. Castanié, D. Felbacq, B. Guizal, Univ. Montpellier 2, CNRS (France)

LIGHT MATTER INTERACTION: STRONG COUPLING AND CAVITY QED II

8095 0X Photonic crystal nanolasers with nanoslot structure for sensing applications (Invited Paper) [8095-30]

T. Baba, S. Kita, H. Abe, S. Hachuda, M. Narimatsu, S. Otsuka, K. Nozaki, Yokohama National Univ. (Japan) and CREST (Japan) 
8095 OY Active semiconductor nanophotonics based on deterministic quantum wire and dot systems (Invited Paper) [8095-31]

P. Gallo, K. Atlasov, M. Calic, B. Dwir, M. Felici, Ecole Polytechnique Fédérale de Lausanne (Switzerland); F. Karlsson, Linköping Univ. (Sweden); A. Mohan, Ecole Polytechnique Fédérale de Lausanne (Switzerland); E. Pelucchi, Tyndall National Institute (Ireland); A. Rudra, V. Savona, A. Surrente, G. Tarel, Q. Zhu, E. Kapon, Ecole Polytechnique Fédérale de Lausanne (Switzerland)

\section{NON-CLASSICAL PHOTONICS: SINGLE PHOTON GENERATION, DETECTION, AND} MANIPULATION

809516 Nonlinear optics near the single photon level with quantum dots coupled to photonic crystals (Invited Paper) [8095-40]

E. Waks, D. Sridharan, R. Bose, H. Kim, T. Shen, G. Solomon, Univ. of Maryland, College Park (United States)

\section{ACTIVE PHOTONIC CIRCUITRY AND DEVICES I}

809518 fJ/bit photonic platform based on photonic crystals (Invited Paper) [8095-43]

M. Notomi, NTT Basic Research Labs. (Japan)

809519 Low power consumption electrically pumped photonic crystal membrane devices (Invited Paper) [8095-44]

B. Ellis, Soraa, Inc. (United States); G. Shambat, Stanford Univ. (United States); M. Mayer, Lawrence Berkeley National Lab. (United States) and Univ. of California, Berkeley (United States); J. Petykiewicz, T. Sarmiento, J. Harris, Stanford Univ. (United States); E. Haller, Lawrence Berkeley National Lab. (United States) and Univ. of California, Berkeley (United States); J. Vuckovic, Stanford Univ. (United States)

\section{ACTIVE PHOTONIC CIRCUITRY AND DEVICES II}

8095 1B Integrated metaphotonics (Invited Paper) [8095-45]

A. D. Boardman, P. Egan, R. C. Mitchell-Thomas, Univ. of Salford (United Kingdom); M. McCall, Imperial College London (United Kingdom); Y. G. Rapoport, Kyiv Taras Shevchenko National Univ. (Ukraine)

8095 1C Active plasmonic devices enhanced by waveguide dispersion engineering [8095-46] C. Min, G. Veronis, Louisiana State Univ. (United States)

8095 1D Slow light using negative metamaterials (Invited Paper) [8095-47]

W. T. LU, Y. J. Huang, S. Sridhar, Northeastern Univ. (United States)

\section{FABRICATION OF ACTIVE PHOTONIC STRUCTURES}

8095 IG Mesoporous Bragg reflectors: block-copolymer self-assembly leads to building blocks with well defined continuous pores and high control over optical properties [8095-50] S. Guldin, Univ. of Cambridge (United Kingdom); M. Kolle, Univ. of Cambridge (United Kingdom) and Harvard Univ. (United States); M. Stefik, Cornell Univ. (United States) and Ecole Polytechnique Fédérale de Lausanne (Switzerland); U. Wiesner, Cornell Univ. (United States); U. Steiner, Univ. of Cambridge (United Kingdom) 
$80951 \mathrm{~J}$ Thermal tuning of a silicon photonic crystal cavity infilled with an elastomer [8095-53]

A. K. Erdamar, M. M. van Leest, S. J. Picken, J. Caro, Technische Univ. Delft (Netherlands)

$80951 \mathrm{~K}$ Mode of propagation of optical radiation with self-similar pulse shape in layered medium with nonlinear absorption [8095-54]

V. A. Trofimov, O. V. Matusevich, D. A. Smotrov, Lomonosov Moscow State Univ. (Russian Federation)

$80951 \mathrm{~N}$ The effects similar to quantum teleportation and superluminality at propagating of laser pulse in medium with combined nonlinear response [8095-57]

V. A. Trofimov, O. V. Matusevich, Lomonosov Moscow State Univ. (Russian Federation)

Author Index 


\title{
Conference Committee
}

\author{
Symposium Chairs
}

David L. Andrews, University of East Anglia Norwich (United Kingdom)

James G. Grote, Air Force Research Laboratory (United States)

Conference Chairs

Ganapathi S. Subramania, Sandia National Laboratories (United States)

Stavroula Foteinopoulou, The University of Exeter (United Kingdom)

Program Committee

Paul V. Braun, University of Illinois at Urbana-Champaign (United States)

Allan Chang, Lawrence Berkeley National Laboratory (United States)

Shanhui Fan, Stanford University (United States)

Stephen H. Foulger, Clemson University (United States)

Rachel Jakubiak, Air Force Research Laboratory (United States)

Michal F. Lipson, Cornell University (United States)

Cefe López, Consejo Superior de Investigaciones Científicas (Spain)

Michael Joseph Sailor, University of California, San Diego (United States)

Daniel M. Wasserman, University of Massachusetts Lowell (United States)

Ralf Boris Wehrspohn, Martin-Luther-Universität Halle-Wittenberg (Germany)

Pierre Wiltzius, University of Illinois at Urbana-Champaign (United States)

Session Chairs

1 Gain Material Dynamics in Patterned Electromagnetic Environment Igal Brener, Sandia National Laboratories (United States)

2 Functional Photonic Materials

Ortwin Hess, Imperial College London (United Kingdom)

3 Non-linear Phenomena and Devices

Alexander V. Kildishev, Purdue University (United States)

$4 \quad$ Dynamic Control of Complex Photonic Media

Allan D. Boardman, University of Salford (United Kingdom) 
$5 \quad$ Magneto-photonic and PT Symmetric Media

Stavroula Foteinopoulou, The University of Exeter (United Kingdom)

$6 \quad$ Lasing in Random Photonic Media

Ganapathi S. Subramania, Sandia National Laboratories (United States)

$7 \quad$ Light Matter Interaction: Strong Coupling and Cavity QED I

Masaya Notomi, NTT Basic Research Laboratories (Japan)

$8 \quad$ Light Matter Interaction: Strong Coupling and Cavity QED II

Marko Loncar, Harvard University (United States)

9 Photon Harvesting for Energy Applications

Ralf Boris Wehrspohn, Martin-Luther-Universität Halle-Wittenberg (Germany)

10 Non-classical Photonics: Single Photon Generation, Detection, and Manipulation

Kai-Ming Ho, lowa State University (United States)

11 Active Photonic Circuitry and Devices I

Didier Felbacq, Universite Montpellier 2 (France)

12 Active Photonic Circuitry and Devices II

Andrey A. Sukhorukov, The Australian National University (Australia)

13 Fabrication of Active Photonic Structures

Otto L. Muskens, University of Southampton (United Kingdom) 


\section{Introduction}

Artificially structured materials can enable unprecedented and dramatic control of electromagnetic energy, offering unique possibilities in light matter interaction. The extra-ordinary properties of these complex photonic media emanate from the material composition of their constituents as well as their patterned features. Incorporation of active components, such as gain or non-linear materials can enhance the functionality of these advanced photonic materials to a higher level. Active complex photonic media are most promising platforms opening up new possibilities in a wide range of applications including biological/chemical sensing, nanoscale thresholdless lasing, solid state lighting as well as chipscale optical computing. This vast potential for high impact applications has been a driving force in active photonic materials research.

This symposium has brought together theorists and experimentalists to exchange state-of-the art results in this rapidly growing area of research. In particular, the many engaging presentations encompassed a wide range of topics including gain material dynamics in complex photonic media, novel magnetophotonic phenomena, slow light and non-linear waveguides, strong coupling and cavity QED systems as well as non-classical photonic platforms and single photons.

As conference chairs, we would like to express our sincere thanks to all the participants of the 8095 conference who contributed with their presentations as well as manuscripts to make this conference a successful and truly interesting event.

Ganapathi S. Subramania Stavroula Foteinopoulou 
Downloaded From: https://www.spiedigitallibrary.org/conference-proceedings-of-spie on 26 Apr 2023

Terms of Use: https://www.spiedigitallibrary.org/terms-of-use 